\title{
Changes in the magnitude of simultaneous brightness contrast as a function of extended practice
}

\author{
KENDON SMITH and MARILYN GUILKEY \\ University of North Carolina, Greensboro, North Carolina 27412
}

In 35 sessions of 10 trials apiece, each of eight Ss viewed and judged a display which produced simultaneous brightness contrast. All Ss were given an instructional set toward realistic perception. Members of one subgroup were informed as to the magnitude of their judgments; members of another were not. For every $S$, there occurred highly significant changes in magnitude of simultaneous brightness contrast over time. There were wide individual differences in the nature of the changes, not all of which were decremental. No significant differences were found as between informed and noninformed groups. The results are viewed as giving limited support to the notion of learning in the perception of simultaneous brightness contrast.

Although cautionary notes have been sounded (e.g., Brown \& Mueller, 1965; Steger, 1968), there persists a tendency to explain visual contrast phenomena simply in terms of lateral inhibition within the retina (Hurvich \& Jameson, 1964; Ratliff, 1965; Békésy, 1967). This practice extends to the specific phenomenon of simultaneous brightness contrast. In view of that fact, it is interesting that several recent studies (Berman \& Leibowitz, 1965; Parrish \& Smith, 1967; Coren, 1969) have demonstrated that the magnitude of simultaneous brightness contrast depends materially upon attitudinal and judgmental factors. It would thus appear that simultaneous contrast is not entirely a retinal matter, but that it does indeed involve, at least to a degree, Helmholtz's "illusion of judgment [Helmholtz, 1911, p. 295]."

McClure and Smith (1969) have suggested that the extent to which simultaneous brightness contrast is a "judgmental" effect might be ascertainable by measuring its tendency to dissipate with practice (cf. Helmholtz, 1911, p. 295). They point to an analogous situation with respect to the Mueller-Lyer illusion: classically, observers who have known that they were dealing with an illusion have reported a decrement in the Mueller-Lyer effect over repeated trials; the generally accepted explanation for the decrement has been one in terms of perceptual learning and the gradual correction of an error of judgment (see Day, 1962 , and Dewar, $1967 \mathrm{a}$, for recent summaries). In work of their own with simultaneous brightness contrast, McClure and Smith (1969) employed five $\mathrm{Ss}$ who were already acquainted with the effect and who had been instructed to adopt "as critical and objective an attitude as possible toward their task [p. 314]." Each S underwent a total of 500 trials, at the rate of 50 trials per day for 10 successive days. A change in the contrast effect did occur. On the average, however, it was in the direction of increased, rather than decreased, contrast.

McClure and Smith recognize that their findings are anomalous within almost any theoretical framework, and they suggest further clarifying research. The present paper reports such research. Again, repeated exposure to the brightness-contrast situation is the essential operation. Now, however, trials are well distributed, rather than being heavily massed, and a particularly vigorous effort is made, in terms of instructions and procedure, to promote realistic perception.

\section{METHOD \\ Subjects}

The principal Ss were eight graduate students in psychology, familiar generally with simultaneous brightness contrast. Seven were female, one male. The senior author of the present paper served as a supplementary $S$. Participants who normally wore corrective eyeglasses did so during their experimental sessions. 1

\section{Apparatus and Situation}

The central item of apparatus was a Bright nes comparator (Model V-0659). ${ }^{2}$ This device permits the independent control of four achromatic electroluminescent plaques: two disks, each of $10.5 \mathrm{~cm}$ diam, and an annulus of $20 \mathrm{~cm}$ outer diam, surrounding each disk. The range of luminance for each plaque is 0-5 fL.

The luminances involved in the experiment were checked periodically with a Macbeth nluminometer. A Wollensak Model T-1500 tape recorder was used to deliver formal instructions.

All sessions were conducted in a small lightproof experimental room. The $S$ sat in an upholstered chair. At a distance of about $195 \mathrm{~cm}$ before him, the two disks with their surrounding annuli were mounted in his frontal plane. The diameter of each disk intercepted a visual angle of $3 \mathrm{deg}$, $5 \mathrm{~min}$; that of each annulus, $5 \mathrm{deg}$, $50 \mathrm{~min}$. The two displays were $22 \mathrm{~cm}$ (6 deg, $30 \mathrm{~min}$ ) apart and $100 \mathrm{~cm}$ above the floor (i.e., at $S$ 's eye level), on centers. A tunnel, $76 \times 30 \mathrm{~cm}$ in cross section and constructed of black velvet, extended from a point directly before $S$ to the visual display; the length of the tunnel was $185 \mathrm{~cm}$. The velvet reduced to negligibility all reflections from the display.

Directly behind S's chair was E's desk, upon which stood the Brightness Comparator control unit and the tape recorder. Illumination for $E$, who was always the junior author of the present report, was provided by miniature lamps which did not affect $S$. Operation of the control unit was soundless.

\section{Procedure}

Each $S$ participated in 35 sessions of 10 trials apiece. A typical session lasted 15 or $20 \mathrm{~min}$. Sessions were spaced at least $24 \mathrm{~h}$ apart. Scheduling was done to suit S's convenience, and varied somewhat among $S$ and at different times for the same $S$. Overall periods of service ranged from 91 to 165 days.

When $S$ appeared for his first session, he was seated in his chair, the room was darkened, and he underwent a 5-min dark-adaptation period. Then, with S's eyes closed, the visual display was adjusted for the first trial: the disk on S's right was set at $1 \mathrm{fL}$, the annulus on his right was left totally dark, and the annulus on his left was set at $3 \mathrm{fL}$, these three settings remaining constant for all Ss during the entire study; the disk on S's left was set at some value other than $1 \mathrm{fL}$, following a procedure, described below, which was also a regular feature of the entire study. $\mathbf{S}$ was then instructed to open his eyes and listen to tape-recorded instructions.

The instructions identified the right-hand disk as the standard, and told $S$ to change the left-hand disk on each trial, by giving instructions to $\mathrm{E}$, until it appeared to be equal in brightness to the standard. These initial instructions emphasized the essentially phenomenal nature of the judgment required and urged $S$ to make an adjustment which "looked right" to him personally. 

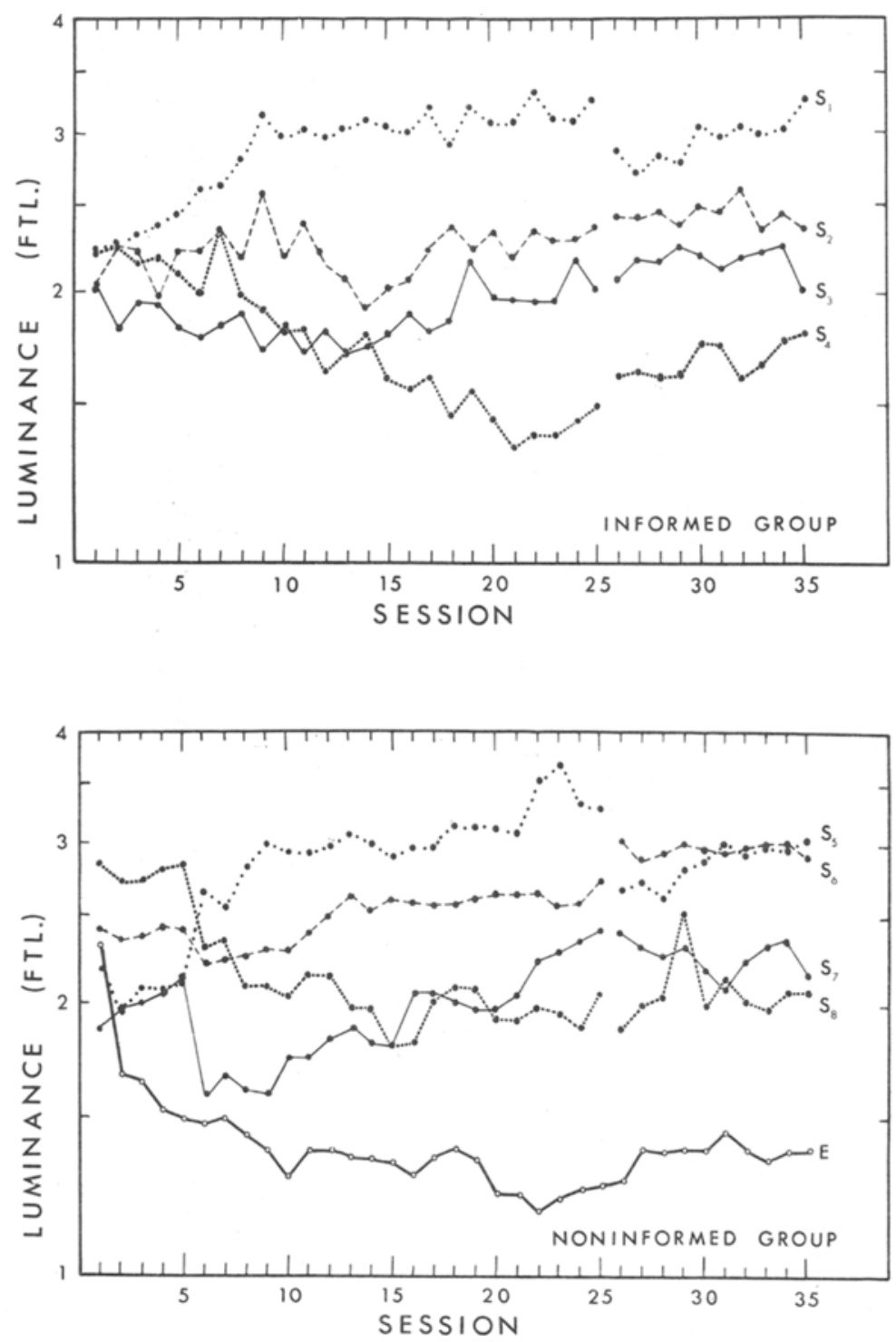

Fig. 1. Mean luminance setting of the variable disk for each session, for each $\mathbf{S}$ in each group and for E. See text for explanation.

$S$ then performed the 10 trials which constituted his first session. In this and in every other session, 5 trials were ascending and 5 trials were descending (although $\mathbf{S}$ was free to reverse direction as often as necessary in making his judgment); the order of ascending and descending trials was governed by a table of random numbers, with the restriction that no more than three successive trials should follow the same direction. Ascending trials began at a luminance of $0.6,0.8$, $1.0,1.2$, or $1.4 \mathrm{fL}$; descending trials began at a luminance of $3.2,3.4,3.6$, 3.8 , or $4.0 \mathrm{fL} ; 3$ initial luminances were assigned to trials in pseudorandom order. S's eyes were always closed as the luminance of the variable disk was being adjusted for the beginning of any trial; and a 5-min dark-adaptation period always initiated each session.

Each $S$ underwent his first five sessions without further instruction. At the beginning of his sixth session, immediately following the dark-adaptation period, he was given additional information and directions. Again through the use of a tape recording, $S$ was reminded that simultaneous brightness contrast was "... a sort of an illusion, and ... a very compelling one." The experimental apparatus was used to give, in coordination with the tape-recorded material, several d e m onstrations of the brightness-contrast effect. $S$ was then asked to continue making the same sort of judgment he had already been making for the first five sessions, but now ". . to be constantly aware of the misleading effect of the bright ring, .... [to] try to ignore that bright ring as much as possible, and concentrate on the two disks themselves." That is, he was to attempt to make his judgments both (1) as purely perceptual and (2) as critical and realistic as possible.

For four of the $\mathrm{Ss}$, chosen at random, the new instructions ended at that point. The remaining four Ss were further told: "In this phase of the experiment, also, you will be given additional information. After you make each setting, we will tell you what that setting is: 80 units of illumination [the instrument's dials were calibrated in arbitrary units, related linearly to actual luminance], or 65 , or 73 , or whatever. You can compare your settings with the objectively correct setting, which happens to be 50 units of illumination ... [Be sure, however, to] pick out a setting at which the two disks do look truly alike to you, personally. You are always making a judgment of phenomenological, perceptual equality." The new instructions thus created two subgroups of four $S$ apiece: the informed group and the noninformed group.

The Ss continued under the routines indicated through Session 25. Between Session 20 and Session 21, every $S$ was interviewed in a nondirective fashion, to gain an idea of what his own procedures and experiences had been to that point. The interviews indicated that, except for two Ss (identified below as S 2 and S 5), every $S$ had been fixating the two disks successively as he reached his decision. Beginning no later than the second session, Ss 2 and 5 had each settled on a technique involving fixation of an arbitrary point on the display. On the basis of the interviews, it was decided to give further instructions to all Ss, by tape recorder, at the beginning of Session 26.

The new instructions were firm in requiring fixation upon the disks themselves. It was emphasized that the perceptual judgment should be made by looking alternately at the two disks and that judgments involving any sort of peripheral vision were to be avoided. Under these final instructions, the $S s$ carried out Sessions 26-35. At that point, their experimental service was finished, although informal discussions were subsequently held with several of them.

The senior $\mathrm{E}$ was noninformed, and he followed throughout the routine of alternating fixations upon the two disks.

\section{RESULTS}

Figure 1 summarizes the results of 
the procedure just described. The upper panel presents the session means in foot-lamberts plotted logarithmically, for each member of the informed group; the lower panel presents similar data for the noninformed group and for $E$. The curve for every $S$ is broken after Session 25, the point at which additional instructions were given. It is to be noted that an increase in luminance value represents an increase in simultaneous contrast effect, inasmuch as a greater brightening of the variable disk is being required to offset the darkening effect of its annulus; a decrease in luminance indicates a decrease in the contrast effect. The luminance of the standard disk (the veridical value for the variable disk) is represented by the level at which the abscissa is drawn ( $1 \mathrm{fL}$ ); the luminance of the annulus surrounding the variable disk is represented by an ordinate value of $3 \mathrm{fL}$.

The data for the eight principal Ss were submitted to an analysis of variance for repeated measures under two conditions. Separate analyses were performed for Sessions 1-25 and for Sessions 26-35. For the first block of sessions, nonsignificant Fs were obtained for the main effects of information ( $\mathrm{df}=1,6)$ and of trials ( $\mathrm{df}=24,144)$, and for the interaction between the two $(\mathrm{df}=24,144)$, as well. A corresponding analysis for Sessions 26-35 also showed no significant relationships.

In spite of the general lack of significance in terms of mean effects, the underlying individual effects were highly significant. A one-way analysis of variance over Sessions 1-25 was done individually $(\mathrm{df}=24,225)$ for each S. In every case, $p<.01$; the result for $E$ was the same. $A$ corresponding analysis for Sessions 26-35 showed five cases in which $\mathrm{p}<.01$ (Ss 1, 3, 5, 7, and 8), one case in which $\mathrm{p}<.05$ (S 4), and two in which $p$ was not significant (Ss 2 and 6 ). The probability of obtaining by chance as many as six differences out of eight at the .05 level is less than .0001 (Wilkinson, 1951). For E individually, $\mathrm{p}<.05$.

There is an apparent discontinuity in the Ss' records, as between Sessions 25 and 26. That discontinuity was explored statistically. A two-tailed $t$ test was performed for each $S$, determining the likelihood of a difference as large as that found between his mean judgments for Sessions 25 and 26 arising by chance alone. Four individual $p$ values were thus generated for each group. One of the differences in the informed group (that for $S 1$ ) was significant beyond the .01 level; one other (S 4) was significant above the .05 level; the probability of obtaining two such differences among only four cases is .01 (Wilkinson, 1951). Three of the differences (Ss 5,6 , and 8 ) in the noninformed group were significant beyond the .01 level, yielding a joint $\mathrm{p}<.0001$ (Wilkinson, 1951).

Qualitatively speaking, the individual curves of Fig. 1 differ rather strikingly from one another. Only three (Ss 4, 8, and E) show the downward trend, toward veridicality, which was anticipated. Three others (Ss 1, 5, and 6) show rather distinct upward trends, the former two Ss actually, for a large number of trials, choosing settings of the variable disk which made it more luminous than its surrounding annulus. It will be noted that the extreme upward and downward changes all fall within Sessions 1-25; and that, on the logarithmic scale employed in Fig. 1, those changes are approximately symmetrical, representing either a multiplication or a division of the original judgment by a factor of roughly 1.5 .

\section{DISCUSSION AND CONCLUSIONS}

In discussing the present study and its results, two initial comments on method may be in order:

(1) Although the original instructions to $\mathrm{S}$ did tend to imply that he should reach his judgments by fixating the two disks in repeated alternation, $\mathbf{S}$ was actually free to use any mode of inspection (and any duration) that seemed convenient to him. Seven of the nine participants did in fact use the technique of alternating fixation throughout. Through Session 25, the two remaining participants, Ss 2 and 5, employed the technique of fixating steadily an arbitrary point on the display. There were thus some differences between individuals in respect to mode of viewing during Sessions 1-25; nevertheless, each individual seems to have followed his own mode quite consistently during these sessions. The more definite instructions under which Sessions 26-35 were run were intended to impose upon Ss 2 and 5 the same observational conditions under which the other participants were working and to assess the effect of such an imposition. The new instructions appear to have had a transitory disruptive effect upon the $S s$ in general; but Ss 2 and 5 were not basically affected in their subsequent performance. All in all, it would appear that individual differences in style of viewing do not pose a problem to the interpretation of the present results.

(2) Throughout and repeatedly, instructions to $S$ emphasized that he was to report his immediate perceptions rather than his intellectualized conclusions. We are confident that the Ss did so. Testimony in that direction is provided by the lack of significant effects of informative feedback and by the relative infrequency of judgments of decreasing magnitudes; furthermore, interviews with the members of the informed group, between Sessions 20 and 21, indicated that none of them was much concerned with the objective accuracy of his judgments. There is thus no evidence that the $S$ s were attempting to "correct" their reports in the direction of reality. Granting that they were not, we feel that the use of a strong experimental set toward realistic perception (which is hardly unprecendented) and even of frank information as to accuracy were justified.

Substantively, the results of the present investigation suggest that the outcome of the McClure and Smith (1969) study was actually not particularly idiosyncratic. It probably did not depend heavily, as we had surmised it might have, upon a radical massing of trials or upon any failure to convey emphatic instructions to $S$; the results obtained now, with widely distributed trials and unmistakable instructions, are not greatly different. Beck's (1966) finding (using five Ss over a period of 6 days) that simultaneous brightness assimilation moves, under some conditions, toward contrast, also seems essentially consonant with the present results. In both the McClure and Smith and the Beck studies, it might be pointed out, the number of Ss was very small (i.e., five). Considering the range of individual differences which is now evident, the opportunities for error of random sampling must have been rather large in both cases. Thus, in either study, the choice of Ss who happened to tend toward the enhancement of contrast would not have been an improbable event; and neither investigation employed statistics sensitive to this sort of sampling error.

In general terms, the outcome of the present investigation indicates that simultaneous brightness contrast changes significantly and sometimes considerably with repeated viewing experience. It is difficult to account for such change, especially when it takes a consistently upward or downward course, in any obvious "physiological" terms. The case in favor of contrast as a "psychological" phenomenon is thus somewhat strengthened. It is interesting that very recent research (De Valois \& Pease, 1971) at the electrophysiological level 
has led to a parallel conclusion: "The center-surround organization of the cells' receptive fields should, we believe, be considered as a contour-enhancing mechanism. Except perhaps for very small visual objects, it does not produce brightness (or color) contrast. For that effect some other presumably cortical process must operate upon the border information [p. 696]."

To say that a phenomenon is "psychological" is presumably to say that it is susceptible to modification by learning; but a rather striking feature of the present results is their failure to reflect the nature of the external motivation and reinforcement imposed upon the Ss. If the curves of Fig. 1 represent learning, it is learning which is highly autonomous. By way of comparison, however, it may be noted that, although the older reports on practice with the Mueller-Lyer illusion emphasized decremental trends, such trends have by no means been invariable; both lack of change and enchancement have been com mon, especially when comparatively naive $S$ s have been used (Day, 1962; Dewar, 1967a, b; Eysenck \& Slater, 1958). It thus appears that new and more potent techiques will be required, if the shaping of perception toward reality is to be clearly demonstrated in the laboratory. 4

\section{REFERENCES}

BECK, J. Contrast and assimilation in lightness judgments. Perception \& Psy chophysics, 1966, 1, 342-344.

BEKESY, G. v. Sensory inhibition. Princeton: Princeton University Press, 1967.
BERMAN, P. W., \& LEIBOWITZ, H. W. Some effects of contour on simuitaneous brightness contrast. Journal of Experimental Psychology, 1965, 69 251-256.

BROWN, J. L., \& MUELLER, C. G. Brightness discrimination and brightness contrast. In C. H. Graham (Ed.), Vision and visual perception. New York: Wiley, 1965.

COREN, S. Brightness contrast as a function of figure-ground relations. Journal of Experimental Psychology, 1969, 80, 517-524.

$D A Y, R$. H. The effect of repeated trials and prolonged fixation on error in the Müller-Lyer figure. Psychological Monographs, 1962, 76 (Whole No. 533)

De VALOIS, R. L. \& PEASE, P. L Contours and contrast: Responses of monkey lateral geniculate nucleus cells to luminance and color figures. Science. 1971, 171, 694-696.

DEW AR, R. E. Stimulus determinants of the practice decrement of the Miller-L yer illusion. Canadian Journal of Psychology, 1967a, 21, 504-520.

DEWAR, $R$. E. The effect of angle between the oblique lines on the decrement of the $M$ üller-Lyer illusion with extended practice. Perception \& Psychophysics, $1967 b, 2,426-428$.

EYSENCK, H. J., \& SLATER, P. Effects of practice and rest on fluctuations in the Müller-Lyer illusion. British Journal of Psychology, 1958, 49, 246-25 6.

HELMHOL TZ, H. v. Handbuch der Physiologischen Optik. Zweiter Band (Dritte Auflage). Hamburg and Leipzig: Leopold Voss, 1911. Seen as Southall J. P.C. Helmholtz's treatise on physiological optics, translated from the third German edition, volume 2 . New York: Dover Publications, 1962.

HURVICH, L. M. \& JAMESON, D. Introduction. In L. M. Hurvich and $D$. Jameson, Outlines of a theory of the light sense. Cambridge: Harvard University Press, 1964. (Translation of $E$. Hering. Grundzüge der Lehre vom Lichtsinn。 Berlin: Springer, 1920.)

MCCLURE, G., \& SMITH, K. Simultaneous brightness contrast as a function of repeated trials. Psychonomic Science, $1969,16,314-315$.

PARRISH, M \& SMITH, K. Simultaneous brightness contrast as a function of perceptual set. Psychonomic Science, 1967, 7, 155-156.

RATLIFF, F. Mach bands: Quantitative studies on neural networks in the retina. San Francisco: Holden-Day, 1965.

STEGER, J. A Reversal of simultaneous ligh tness-contrast. Psy chological Bulletin, 1968, 70, 774-781.

WILKINSON B. A statistical consideration in psychological research. Psychological Bulletin, 1951, 48, 156-158.

\section{NOTES}

1. We wish to acknowledge with gratitude the generous assistance of our Ss: Pamlyn Atkins, Patricia Johnson, Fran Longo, Judith Rand, Minta McCollum Saunders, Lenin Salmon, Lynda Wilson, and Gayle Wunder Hock.

2. Purchased from Polymetric Products, Itek Corporation, 10 Maguire Road, Lexington, Massachusetts. Now available from the Polymetric Company, 1415 Park Avenue, Hoboken, New Jersey 07030 .

3. For a few Ss, who eventually reached comparatively extreme ranges of values, it was necessary to modify the initial luminances appropriately.

4. It is difficult to see how even perceptual learning can proceed without some sort of "knowledge of results." In the present study, only the informed group was given such knowledge. The noninformed group was not; nor is the typical $S$ in any perceptual learning experiment. It is pertinent, then, that the two members of the noninformed group in the present investigation who showed the most extreme records ( 5 and $E$ ) both reported having had some insight into the trend of their judgments, from session to session. They often realized, on the basis of absolute memory, that their settings during a given session were generally higher or lower, respectively, than they had been a session or two before. They were thus aware, to a degree, of the efficacy of their own performances.

(Accepted for publication July 10, 1971.) 